\title{
Field Practice, Emerging Technologies, and Human Rights: the Emergence of Tech Social Workers
}

\author{
Siva Mathiyazhagan ${ }^{1}$ (D) \\ Accepted: 21 July 2021 / Published online: 9 September 2021 \\ (c) The Author(s), under exclusive licence to Springer Nature Switzerland AG 2021
}

\begin{abstract}
Structural inequalities, historical oppression, discrimination, social exclusion, power, and privilege are some of the most pressing human rights issues that social workers deal with in everyday practice. In the recent past, all these issues are not only prevalent in offline communities, but they are also active in online communities. The digital divide and online polarizations perpetuate power and privilege within and outside of social work practice. Social work practices are moving beyond boundaries, expanding, and adopting emerging technologies in all aspects of social work education, research, and practice. This paper has been prepared based on my last decade of transnational social work practice experience and fieldwork supervision. There is an emerging need for tech social work practices in all fields of social work. This paper discusses the challenges and opportunities for tech social work in the field and explores a possible model for tech social work practice to support safe and inclusive communities on and offline to promote human rights.
\end{abstract}

Keywords Tech social work $\cdot$ Fieldwork $\cdot$ Human rights $\cdot$ Technology $\cdot$ Artificial intelligence

\section{Introduction}

Social work practices are moving beyond boundaries, expanding, and adopting emerging technologies in all aspects of social work education, research, and practice. Globalization and technological advancements are opening new avenues and opportunities for social workers around the world (Panos, 2005). In today's online world, there are 4.57 billion internet users globally and 3.81 billion active social media users (Kemp, 2020). Youth in the age group of 15-24 are the most connected, and one in three internet users are children and adolescents (UNICEF, 2017). Fieldwork agencies are also advancing their clinical, family, and community-based practices with different technologies, particularly during the COVID-19 pandemic. However, there is only a $3 \%$ chance of automating social work jobs; that is to say, it is difficult work for robots to do (Bui, 2015). Social workers' engagement in technology has become imperative. I have

Siva Mathiyazhagan

dr.siva@tyclinternational.org

1 Trust for Youth and Child Leadership (TYCL) International, New York, USA been a field instructor for social work students from India, Europe, and the USA. As a professional social worker from a marginalized indigenous community in India, embracing and advocating for human rights and social justice in my personal life, social work practice, and field instruction, I have observed emerging trends in social work practice. In the digital era, human rights violations fueled on social media lead to offline violence. There is a significant shift in the digital behavior of young people which is paving a path for social workers' role in technology. As a field instructor, I am always thinking and reflecting with my students on the future of social work practice, research, and education for human rights and social justice with emerging technologies like artificial intelligence (AI).

Structural inequalities, historical oppression, discrimination, social exclusion, power, and privileges are some of the most pressing human rights issues that social workers deal with in everyday practice. In the recent past, these issues are active in online communities. Emerging technologies have been observed to cause major human rights challenges in society, such as (a) e-incarceration and e-surveillance on social media; (b) online abuse and bullying; (c) bias in facial recognition technology leading to discrimination towards people of color; and (d) limited diversity, access, and equal opportunity in the technology space (Benjamin, 2019; 
Buolamwini et al., 2020; Minow et al., 2019; Noble, 2018; Patton et al., 2017). The critical questions for me as a social work practitioner and field instructor include:

1. How are human rights, social justice, and social inclusion practiced and promoted online?

2. What would be the role of social workers in technology?

3. Are emerging technologies recolonizing?

4. How are social work students from various parts of the world responding to these issues?

5. Can tech social workers play a role in securing and protecting safe and inclusive online spaces?

The digital divide and online polarizations perpetuate power and privileges within and outside social work practice. This paper has been prepared based on my last decade of transnational social work practice experience and fieldwork supervision. Although social work field supervision is a particularly important core component of social work education, there is no clear model for social work field practice with emerging technologies. This paper will share some of the critical reflections on emerging technologies based on my transnational social work practice with a youth-led organization called Trust for Youth and Child Leadership (TYCL). This article acknowledges pressing human rights issues existing in emerging technologies and does not claim technology as a universal solution for human rights issues. This article explores the potential scope for budding social workers' engagement with emerging technologies to prevent potential human rights issues such as bias, harm, and digital divide and promote community participation, safety, and inclusion. Social workers' training in the field prepares social work students to ethically address human rights issues in technology and promote a tech social work model for future practices.

\section{Emerging Technology and Social Work}

The digitalization of society has drastically changed people's behavior across our daily lives and in all activities. Digital technologies increase social workers' consciousness around well-equipped skills and competencies for contemporary social work practice (Kirwan, 2019). In the digital era, e-social work is emerging as a new specialization with the adaptation of innovations and new methods for social work practice (López Peláez \& Marcuello-Servós, 2018). There have been several case studies highlighting the use of digital tools in social work education, diagnosis, intervention, and evaluation (Goldkind et al., 2018). Digital social work services, however, are available only in high-income countries, typically target affordable groups, and often require a credit card (Reamer, 2013). In recent years, we have seen more free and subsidized social work services available across the globe, including TYCL's free mental health services to young people in India through a Youth Helpline mobile application. However, the digital divide exists at all levels from geopolitical to household, and social workers can be key actors in analyzing that divide, and developing and implementing solutions (Steyaert \& Gould, 2009). In the growing techdriven society, appropriate assistive technologies certainly create more access to services and compensate for certain impairments of persons with disabilities and the elderly. Similarly, access and ownership to technological tools transform the lives of women in developing counties (The Cherie Blair Foundation for Women \& The GSMA Development Fund, 2013). However, inequality in access to digital technologies generates and replicates socio-economic exclusions (Srivastava, 2019). Social interventions focusing on reducing the digital divide include those which aim to enrich digital skills and promote diverse information producers (Steyaert $\&$ Gould, 2009). There has been an ongoing debate around the ethical use of technology in social work practice. Yet, there has not been much discussion on social work in emerging technologies. Patton et al., (2020a, b) discuss collaboration between social workers and data scientists, and social workers are offered ethical guidelines for social media data research related to youth violence prevention. There is ongoing interdisciplinary research and practice to address pressing human rights issues with social work ethics and principles. Preparing social work students to work with technologies and technologists can become an essential part of social work education and practice to accelerate the human rights agenda.

\section{Human Rights and Technology}

Seven decades after adopting the Universal Declaration of Human Rights (UDHR), this comprehensive global document remains as important even today to reflect on the role technology should play in advancing human rights for all. The personal safety and protection of people in the twentyfirst century demands multi-stakeholder action to address the intersection between technology and human rights (Smith $\&$ Browne, 2018). The World Summit on the Information Society (2003) proclaims that upholding the UDHR is central to build a people-centered, inclusive, and developmentoriented Information Society (ITU, 2003). Increased access to the internet and social media tools has amplified public and activists' voices for human rights (Bloomer, 2020). In the recent past, technologies have enabled and significantly increased freedom of expression for all social groups through social media. However, the COVID-19 global pandemic has made ever more evident the digital divide across society and the inaccessibility of technologies, devices, and internet for poor and marginalized communities to avail 
education, food supplies, health care, mobility, freedom of expression, employment, and communication in several parts of the world. On the other hand, over the course of the pandemic, the world has seen a significant increase in the use of the internet and digital products and services across socio-economic boundaries (IANS, 2020; PCMag, 2020). There are multiple ways technology helps to take the human rights agenda forward. A few examples might be educating youth on human rights and social justice with virtual reality (VR) technology; using artificial intelligence (AI) facial and image recognition technology to prevent crimes against children; and implementing AI tracing technologies to support immigrant laborers and refugees. Social workers are equipped with both theory and practice and are directly connected with marginalized communities. Therefore, tech social work can be critical in overcoming crucial challenges in the tech space, including access, deployment, use, and data bias.

As social work practitioner, I am committed to practicing the following three roles in ensuring human rights in the technological space to move the human rights agenda forward: (a) expanding access to the internet and technology for all as a fundamental human right; (b) ensuring safe, inclusive, and participative technologies for all by engaging marginalized populations; and (c) educating and advocating for policy changes to ensure digital human rights for all. While access to the internet and technologies has drastically increased over the years as part of market expansion, critical questions remain around personal data safety and diversity, inclusion, and marginalized peoples' participation in the development, deployment, and use of the technologies. The rise of AI and technological advancements requires multistakeholder engagement for the ethical use of technology to accelerate human rights with individuals, communities, and organizations. Preparing budding social workers to combat the abovementioned human rights issues in technologies must become an essential part of social work and human rights education.

\section{Identity and Human Rights}

Race and caste are two distinct visible and invisible social and psychological constructions of identities that are vulnerable to human rights violations (Ambedkar, 1917; CháirezGarza \& Ambedkar, 2018). Race is one social identity that is often subject to visible and invisible structural oppression and human rights violations. Caste is one of the most invisible identities, repeatedly subject to encounter visible and invisible oppression and injustice. There has been hope that technology could reduce the structural inequalities in society and amplify equal opportunities for inclusion. While there has been progress to some extent, bias, prejudice, digital divides, and discrimination often exist online as they have in offline communities (Benjamin, 2019; Buolamwini et al., 2020; Noble, 2018). Unfortunately, inequalities show up in every phase of technology development, deployment, access, and usage. This underdiscussed reality has created huge systemic human rights issues online. The fundamental question is, by whom and for whom are these technologies and technological tools created? Students in India and the USA are more comfortable exploring and discussing social identity and intersectionality of race and caste. Most Indian students, however, are hesitant and not prepared to explore questions and expressions of social identity, though this also differs from school to school and by the lived experiences of the students. These unexplored social identities often cause human rights issues in the field. People behind technology are biased, are less diverse, and tend to bypass ethical processes, all of which amplify structural inequalities in technology and cause harm to vulnerable populations (Floridi et al., 2020). The preparation of social work students in the field education requires three layers to address human rights challenges: (a) constant reflection on identity and structural inequalities; (b) adaptation of innovative technological tools in social work practice; and (c) social work ethical contributions to emerging technologies. This type of holistic approach in preparing social students in the field potentially addresses inequalities and amplifies human rights voices in the digital space.

\section{Transnational Social Work Practice}

For the past decade, I have served as founder-director of TYCL, a youth-led organization based in India and the USA working to create safe and inclusive spaces for, by, and with young people. TYCL respects and recognizes indigenous knowledge, culture, and development practices in hybrid social change models that combine indigeneity with modern technologies. This unique approach attracts social work students from all over the world. TYCL is committed to addressing the most pressing issues of young people, such as mental health, violence against children both online and offline, and promoting pro-environmental behavior among young people. TYCL is not only working with young people and their families and communities, but also working with social workers and technologists from different parts of the world to create safe and inclusive spaces for young people online. TYCL has launched a youth helpline mobile application for virtual mental health support and another mobile application for children's mentorship programs with the support of local technologists, social workers, and youth volunteers. These mobile applications have not only expanded the organization's operations, but have also broadened the scope for transnational social work practice and 
virtual support systems for vulnerable young people. My affiliation with social work schools like the Department of Social Work, Pondicherry University in India, and Columbia School of Social Work in the USA has expanded my theoretical knowledge and supported my exploration of the need for triangulated collaboration between youth-led community organizations, social work schools, and tech companies to ensure no one is victimized or criminalized online and to promote safe and inclusive technologies through a social work lens beyond borders.

\section{Fieldwork and Emerging Technologies}

We cannot avoid the implications of technology in our daily lives. As social workers, we have the skills and capacities to collaborate and co-create with technologists, policymakers, and community members (Goldkind et al., 2018). TYCL actively works with social work students in online user research; collaborates with technologists to develop mobile applications and websites; and explores the capacities of technologies to track youth suicidal expressions on social media and prevent cybercrime against children. We have found more scope and opportunities in expanding this work by using ethical artificial intelligence (AI) and machine learning (ML) technologies to support young people online and offline by collaborating with local tech companies. In our application development process, social work students engage in online media analysis, collect secondary data from government departments, and critically analyze data diversity and inclusion in the mobile application development process. These processes helped technologists to build an inclusive architecture for our youth helpline mobile application. Considering indigeneity, education, and language exposure of our youth, we have developed mobile apps with regional language options for easy access. In addition, we enabled video, audio, and text options for youth with disabilities. The active engagement of social work students in tech-related fieldwork assignments has had the following triangular benefits:

1. Students have opportunities to work with technologists and senior social workers to practice social work methods, ethics, and social research online.

2. Social work students' professional and casual engagement with tech developers helps technologists to understand the importance of diversity, inclusion, and biasfree tech tools for young people.

3. The triparty engagement between budding social workers, technologists, and youth-led organizations supports to create access to technologies and advance social work practice ethically with vulnerable communities.
This unique collaboration, including diverse knowledge and skillsets from all stakeholders, has expanded my thoughts and creativity towards tech social workers and the future of social work. youth expressions have been observed online, noticing that in recent years the use of social media has significantly increased, and youth online interaction has escalated more than ever. TYCL receives students specialized in community development, policy, social entrepreneurship, general social work practice, and family and child welfare. There is an emerging need for online social work practice in all of these subfields. All the above-specialized students engaged in different levels of work in the organization and in collaboration with technologists. To provide the training and tools to build their capacity to support, protect, and advance human rights in online spaces as tech social workers, the following examples provide examples of ways in which we have engaged social work students online:

1. Social media research on youth suicide, including online data collection, annotation, qualitative data coding, and developing information, education, and communication (IEC) materials for awareness generation.

2. Re-validating online data with respective families and communities.

3. Designing and piloting new programs online and offline.

4. Working with technologists to analyze application development architecture for inclusion and bias avoidance.

5. Digital mapping of the risk areas for youth suicide and digital sensitizations through social media and Google ads.

6. Mobile virtual mental health support and virtual referrals for in-need youth with potential resources to address socio-economic determinants of suicide.

7. Virtual fieldwork using online social work skills, including process documentation in Google Drive, virtual supervision, and virtual coordination with other stakeholders.

TYCL did not face many challenges to adapt operations and fieldwork in the USA to the "new normal" raised by the COVID-19 pandemic. In India, however, social work schools suspended their classes and fieldwork, though some Indian social work students actively participated in TYCL's virtual "Overcome COVID-19" project work.

\section{Future Possibilities}

TYCL is also planning for the following other possibilities in future fieldwork assignments:

1. TYCL will engage social work students in decoding and annotating youth and children's online expressions (words, emojis, audio, video, symbols, and web content in local/mixed languages and slang words) with the sup- 
port of community experts to understand young people language and expressions (Patton et al., 2020a, b) to develop appropriate tech support for issues like violence prevention, online grooming, and cyberbullying.

2. Social work students will work closely with TYCL's tech partners and technologists to develop social media plugins to detect youth suicide expressions and support young people online. Similarly, TYCL is planning to develop a child abuse prevention web plugin to prevent online grooming and to support children and their families in taking rights-based decisions to ensure safe and inclusive spaces for all children, everywhere.

3. Our current social work student interns are in the process of developing a STREAM (science, technology, rights and responsibilities, ethical engineering, arts, and math) curriculum to support next-generation inclusive, ethical innovators, and technologists from diverse backgrounds. Social workers will be trained to add human rights and social work ethics in STREAM education for children in marginalized communities to develop safe technologies with no bias and harm to people and the planet.

4. Social work interventions through technology are most often offered in English, which makes them inaccessible for countries with diverse populations like India. TYCL is in the process of updating its youth helpline mobile application with multiple local language support for youth who are in mental health need. Social work students will be engaged in the development and deployment of inclusive AI-enabled positive mental health support mobile applications for young people in regional languages across India.

5. TYCL uses visual media technologies with social work skills and participatory action research methods in a childcentered visual SWOT analysis project with marginalized communities, designed for tailor-made sensitization and youth-led community-owned action (Mathiyazhagan, 2020). Looking forward, we are planning to pilot 360-degree virtual reality (VR) to create visual SWOT depictions of the child-centered social justice initiatives in vulnerable communities to promote collective voices for child rights.

These are some of the ways TYCL is currently working with social work interns in the tech field to explore and leverage the opportunities of social work practice to protect human rights with emerging technologies. Significantly, TYCL actively seeks partnership with tech companies to develop web and social media plugins and mobile applications for youth suicide prevention and online child abuse prevention. The companies must be willing to work in partnership with social work students, senior social workers in the organization, and communities in the technology development process.

\section{Challenges in the Field}

As a youth-led organization with limited resources, there are several challenges for the organization as well as for the social work students in adopting and practicing social work with emerging technologies. First, fieldwork days and times differ from country to country and school to school. In India, some schools engage students in fieldwork 2 days a week throughout the semester or for a 1-month field practicum at the end of the semester. In the USA, schools may provide 3 days a week for the whole academic year. It can be challenging for the organization to adjust its operational schedule based on the placement of the student. Most of the schools do not offer orientation or training on emerging technologies and media. This requires a high investment of the organization's time and knowledge to induct the students, but due to limited time, it is not always possible to harvest the maximum fruits of the students' social work skills and abilities in the emerging technology space. Likewise, social work schools have assigned to organizational field instructors' additional academic responsibilities, such as supervising students, task management, process documentation assessments, feedback, evaluation, and career support. These academic requirements consume more time and limit the time available for social work practice and innovation. Some students are more advanced and are willing to do more tech work, but due to resource constraints, there may be limited tech tools available to advance their practices in the organization.

In India, TYCL receives a diverse group of students from different parts of India and from around the world. Many of the students do not know the local language or the social context to understand the community directly, and so many of them are assigned to do backend research and administrative work. While their field education plans may include online research and practice, some of the students argue that online and tech research is not social work research and prefer to seek direct practice with vulnerable communities. A few common challenges observed among the students are a lack of clarity in their learning style and the application of basic and advanced skills of social work in the organization. These students' challenges can be addressed with additional resources and by adjusting the fieldwork duration. In addition, many Indian students faced challenges in using tech tools like Google Drive, Docs, Sheets, e-Classroom, and Meet for virtual collaboration, and many had limited or no access to the internet and tech devices. Social work students from rural and underprivileged backgrounds, especially, have therefore faced multiple challenges in the field. All these challenges have to be addressed and social work practice has to take place within 24-28 fieldwork days in a semester in India. The US model of fieldwork, however, has 
more time for both preparation and practice. In the ongoing modernization of the social work field education curriculum, sufficient time and resources need to be allocated to prepare students for modern tech social work practice.

\section{The Future of Tech Social Workers}

Over the last two decades, there have been a significant number of conversations about digital social work, e-social work, technologies in social work, and ethics in adopting technology in social work education and practice (Fang et al., 2014; Goldkind et al., 2018; Kirwan, 2019; López Peláez \& Marcuello-Servós, 2018; Reamer, 2013; Steyaert \& Gould, 2009). These developing trends and debates contribute to the improvement of ethical standards, skills, and relationship approaches in social work practice. López-Peláez and Díaz (2015) discuss e-Social work as online research, patient treatment (individual therapy, group, and community dynamics), the training and teaching of social workers, and the monitoring of social service programs. These discussions are focused on adopting technology in social work practice. Alternatively, Patton et al., (2020a, b) have discovered opportunities for social work contributions to data science to address human rights issues. In their research, social workers contribute contextual qualitative inputs to social media research (Patton et al., 2020a, b). Data science, likewise, has the potential to improve the scientific approach of qualitative and quantitative social work research and practice (Cariceo et al., 2018). In this context, tech social work can be defined as a specialization within social work which ethically contributes to technology development processes and to the deployment and use of data in various social settings to address harm. Tech social work also emphasizes effectively using technological tools in the process of social work education, training, research, practice, and interventions to promote equity, diversity, human rights, community participation, and social justice with indigenous knowledge and interdisciplinary theories.

As a practitioner-scholar and field instructor, I have observed that there has been increased interest among students in exploring emerging technologies for social work practice. In 2017, the National Association of Social Workers (NASW) in the USA released new standards and ethics for technology use in social work practice (NASW, 2017). In India, however, there is no clear theoretical background or ethical procedures to work with technologists in social work practice. As mentioned above, social work students add value to the tech world by sharing ethical standards of practice for fairer and more just technologies to ensure human rights on digital platforms. Social workers offer combined skills and knowledge in human rights, social justice, and social and environmental ethics. These qualities and skills are widely lacking in the tech sector, which has caused more social issues like racial discrimination in AI products and services and caste-based digital expressions and advertisements, which have resulted in victimization and

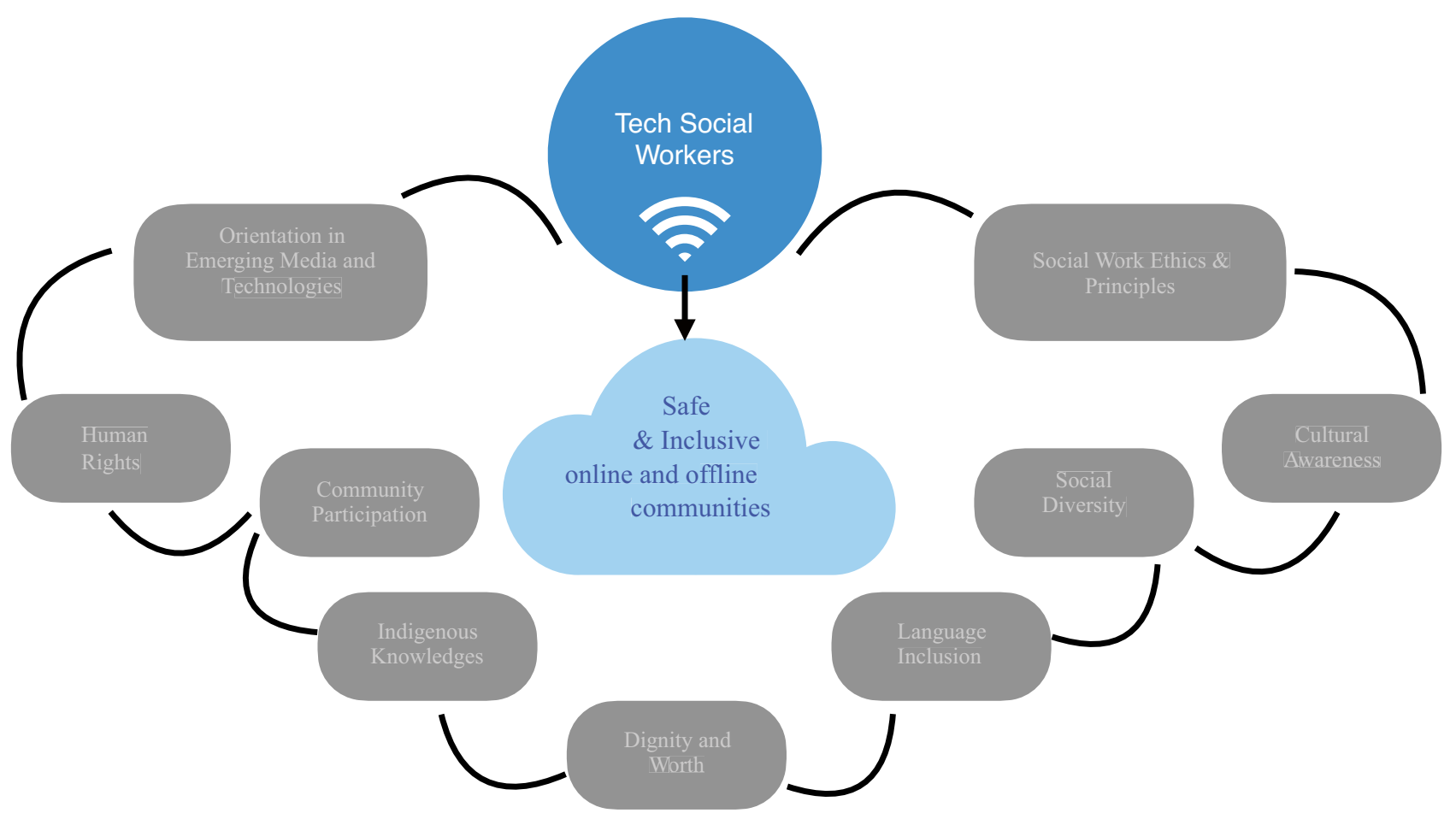

Fig. 1 Social work skills and knowledge to promote human rights in emerging technologies 
criminalization of marginalized communities. Social workers can complement their social skills and knowledge in technologies for social justice. There is an emerging need for engaging social workers in technology development, deployment, and implementation to prevent such consequences in society. Figure 1 below exhibits the qualities and components of tech social workers in the field to ensure safe and inclusive technologies and online communities. Social work schools around the world must incorporate emerging media and technology in the social work curriculum to equip social work students to ensure human rights and social justice in online and tech spaces. Social work schools in India may focus on developing standard fieldwork guidelines and induction programs for fieldwork agencies and field instructors, similar to Seminars in Field Instruction (SIFI) offered in the USA.

Alike to TYCL, there may be ample scope for other development agencies to move practices online and adapt more tech tools for their program implementations in India and beyond. Likewise, social workers are particularly well equipped to take on opportunities in tech companies towards human rights and ethics. Google, for example, was recently hiring social scientists for their ethical AI team. Unlike other disciplines of social sciences, social work includes the unique aspect of field practice with specific direct and indirect methods to work with people using appropriate approaches, principles, and ethics. This makes social workers more than eligible to work in the tech spaces and organizations.

I envision two possible models of tech social works:

- Technology-based social work services and practices online and offline and

- Development and deployment of appropriate technologies for the further expansion of safe and inclusive communities online and offline to upload human rights.

The contextual understanding and analysis of social issues in the tech space and the capacity to address human rights issues in emerging technologies will become reality by promoting tech social workers in the field to support safe and inclusive communities online and offline.

\section{Conclusion}

The ongoing health, economic, and social uncertainties caused by the COVID-19 pandemic re-emphasize the need for social workers who have been trained and acquired competency in online social work practice in micro, mezzo, and macro practice models in the recovery process. There is great potential for social work schools in the USA, India, and globally to expand their coursework available and create specialized tracks in human rights, emerging technology, and media. Fieldwork agencies like TYCL are keen to train social work students to practice with emerging technologies through a human rights lens to bring community participation, cultural context, and language inclusion into the tech tools. It is essential that social work students are sensitized and internalize the visible and invisible identity issues in human rights and cultural contexts. When access to the internet and digital tools becomes a basic right of the people, understanding how caste, oppression, race, power, and privilege (CORPP) impact the technology sector and socio-cultural contexts can add value to human rightsand social justice-driven tech social work practice. Social work schools around the world should incorporate CORPP courses in their curriculum to advance their human rights actions in the field. With AI/ML technologies positioned to lead the market in every aspect of human life and shift human digital behavior, it is time to prepare social workers to work with marginalized people and technologies to promote human rights and social justice (Dobrescu, 2018; Hasse et al., 2019; Patton, 2020). Mainstream technology companies can be potential field partners for social workers along with appropriate guidelines, field supervisors, and academic supervisors. The emergence of tech social workers is the need of the hour, and it requires collective will and action to move this human rights agenda forward. The unique combination of social work with indigenous knowledge and emerging technologies may be a step towards decolonizing social work practice. This unique integrated approach creates an opportunity for tech social work model and specialization within social work education, practice, and research to support safe and inclusive communities online and offline to promote human rights.

\section{References}

Ambedkar, B. R. (1917). Castes in India: their mechanism, genesis, and development. Indian Antiquary Vol. XLI. http://www.columbia. edu/itc/mealac/pritchett/00ambedkar/txt_ambedkar_castes.html

Benjamin, R. (2019). Race after technology Abolitionist tools for the new Jim Code (1st ed.) Polity Press. https://politybooks.com/ bookdetail/?isbn $=9781509526390$

Bloomer, P. (2020). Technology and human rights. The Business \& Human Rights Resource Centre. https://www.businesshumanrights.org/en/technology-and-human-rights

Bui, Q. (2015). Will Your Job Be Done By A Machine? Retrieved December 1, 2020, from NPR website: https://www.npr.org/sections/ money/2015/05/21/408234543/will-your-job-be-done-by-a-machine

Buolamwini, J., Ordonez, V., Morgenstern, J., \& Learned-Miller, E. (2020). Facial recognition technologies: A primer. Algorithmic Justice League. https://www.ajl.org/federal-office-call

Cariceo, O., Nair, M., \& Lytton, J. (2018). Data science for social work practice. Methodological Innovations. https://doi.org/10.1177/ 2059799118814392

Cháirez-Garza, J. F., \& Ambedkar, B. R. (2018). Franz Boas and the rejection of racial theories of untouchability. South Asia: Journal 
of South Asian Studies, 41(2), 281-296. https://doi.org/10.1080/ 00856401.2018 .1431855

Cohen, J. (2020). Data usage has increased 47 percent during COVID19 quarantine. $P C$ Magazine. https://www.pcmag.com/news/datausage-has-increased-47-percent-during-covid-19-quarantine

Dobrescu, E. M. (2018). Artificial intelligence (AI) - The technology that shapes the world. Global Economic Observer, 6(2), 71-81.

Fang, L., Mishna, F., Zhang, V. F., Van Wert, M., \& Bogo, M. (2014). Social media and social work education: Understanding and dealing with the new digital world. Social Work in Health Care, 53(9), 800-814. https://doi.org/10.1080/00981389.2014. 943455

Floridi, L., Cowls, J., King, T. C., \& Taddeo, M. (2020). How to design AI for social good: Seven essential factors. Science and Engineering Ethics, 26(3), 1771-1796. https://doi.org/10.1007/ s11948-020-00213-5

Goldkind, L., Wolf, L., \& Freddolino, P. P. (2018). Digital social work: Tools for practice with individuals, organizations, and communities. Oxford University Press. https://global.oup.com/ushe/product/ digital-social-work-9780190871116

Hasse, A., Cortesi, S., Lombana-Bermudez, A., \& Gasser, U. (2019). Youth and artificial intelligence: Where we stand. Youth and Media, Berkman Klein Center for Internet \& Society. https://cyber. harvard.edu/publication/2019/youth-and-artificial-intelligence/ where-we-stand

IANS. (2020, May 9). Internet traffic in India sees $40 \%$ spike in March due to COVID-19 lockdown: ACT Fibernet. News 18. https://www.news18.com/news/tech/internet-traffic-in-indiasees-40-spike-in-march-due-to-covid-19-lockdown-act-fibernet2612669.html

International Telecommunications Union (ITU). (2003). WSIS: Declaration of principles. http://www.itu.int/net/wsis/docs/geneva/ official/dop.html

Kemp, S. (2020, April 24). Report: Most important data on digital audiences during coronavirus. The Next Web. https://thenextweb. com/growth-quarters/2020/04/24/report-most-important-data-ondigital-audiences-during-coronavirus/

Kirwan, G. (2019). Editorial: Networked relationships in the digital age-messages for social work. Journal of Social Work Practice, 33(2), 123-126. https://doi.org/10.1080/02650533.2019.1608430

López Peláez, A., \& Marcuello-Servós, C. (2018). e-Social work and digital society: Re-conceptualizing approaches, practices and technologies. European Journal of Social Work, 21(6), 801-803. https://doi.org/10.1080/13691457.2018.1520475

López-Peláez, A., \& Díaz, H. L. (2015). Social work challenges in the 21 century: Citizenship, technology and e-Social work. In A. López Peláez (coord.), Social work challenges in the XXI century: Perspectives from the USA (pp. 44-45). Thomson-Reuters Aranzadi.

Mathiyazhagan, S. (2020). Participatory youth-led community development: a child-centered visual SWOT analysis in India. Children and Youth Services Review, 113(2020), 104963. https://doi.org/10.1016/j. childyouth.2020.104963

Minow, M., Zittrain, J., \& Bowers, J. (17 July 2019). Technical flaws of pretrial risk assessments raise grave concerns. https://cyber.harvard. edu/story/2019-07/technical-flaws-pretrial-risk-assessments-raisegrave-concerns

National Association of Social Workers (NASW). (2017). NASW, $A S W B, C S W E, \& C S W$ standards for technology in social work practice. https://www. socialworkers.org/includes/ newIncludes/homepage/PRA-BRO-33617.TechStandards_ FINAL_POSTING.pdf

Noble, U. S. (2018). Algorithms of oppression how search engines reinforce racism (1st ed.) New York University Press. https:// nyupress.org/9781479837243/algorithms-of-oppression/

Panos, P. T. (2005). A model for using videoconferencing technology to support international social work field practicum students. International Social Work, 48(6), 834-841. https://doi.org/10.1177/ 0020872805057095

Patton, D. U., Frey, W. R., McGregor, K. A., Lee, F. T., McKeown, K., \& Moss, E. (2020a). Contextual analysis of social media: The promise and challenge of eliciting context in social media posts with natural language processing. AIES 2020 - Proceedings of the AAAI/ACM Conference on AI, Ethics, and Society, 337-342. https://doi.org/10. $1145 / 3375627.3375841$

Patton, D. U. (2020). Social work thinking for UX and AI design. Interactions, 27(2), 86-89. https://doi.org/10.1145/3380535

Patton, D. U., Blandfort, P., Frey, W. R., Schifanella, R., McGregor, K., \& Chang, S. F. U. (2020b). Vatas: An open-source web platform for visual and textual analysis of social media. Journal of the Society for Social Work and Research, 11(1), 133-155. https://doi.org/10. 1086/707667

Patton, D. U., Brunton, D. W., Dixon, A., Miller, R. J., Leonard, P., \& Hackman, R. (2017). Stop and frisk online: Theorizing everyday racism in digital policing in the use of social media for identification of criminal conduct and associations. Social Media and Society, 3(3). https://doi.org/10.1177/2056305117733344

Reamer, F. G. (2013). The digital and electronic revolution in social work: rethinking the meaning of ethical practice. Ethics and Social Welfare, 7(1). https://doi.org/10.1080/17496535.2012.738694

Smith, B., \& Browne, C. A. (2018). The universal declaration of human rights: An important anniversary for people and for technology. https://blogs.microsoft.com/today-in-tech/the-universaldeclaration-of-human-rights-an-important-anniversary-forpeople-and-for-technology/

Srivastava, S. (2019, September 24). Inequality of another kind. The Hindu. https://www.thehindu.com/opinion/op-ed/inequality-ofanother-kind/article29492512.ece

Steyaert, J., \& Gould, N. (2009). Social work and the changing face of the digital divide. The British Journal of Social Work, 39(4), 740-753. https://doi.org/10.1093/bjsw/bcp022

The Cherie Blair Foundation for Women, \& The GSMA Development Fund. (2013). Women \& mobile: a global opportunity: A study on the mobile phone gender gap in low and middle-income countries. https:// www.gsma.com/mobilefordevelopment/wp-content/uploads/2013/01/ GSMA_Women_and_Mobile-A_Global_Opportunity.pdf

UNICEF. (2017). The state of the world's children - Children in a digital world. https://www.unicef.org/publications/files/SOWC_ 2017_ENG_WEB.pdf 